\title{
Design and Built a Research AUV Solar Light Weight
}

\author{
Ali Razmjoo', Mohammad Ghadimi², Mehrzad Shams ${ }^{3}$, Hoseyn Shirmohammadi ${ }^{4}$ \\ ${ }^{1}$ Department of Energy Systems Engineering, Faculty of Engineering, Islamic Azad University-South Tehran Branch, Iran \\ ${ }^{2}$ Department of Mechanical Engineering, Islamic Azad University, roudehen branch Tehran, Iran \\ ${ }^{3}$ Mechanical Engineering Faculty, Energy Conversion Group, K. N Toosi University of technology, Tehran, Iran \\ ${ }^{4}$ Department of industrial Engineering, West Tehran Branch, Islamic Azad University, Tehran, Iran
}

Email address:

Razmjoo.eng@gmail.com (A. Razmjoo),m.ghadimi@riau.ac.ir (M. Ghadimi)

\section{To cite this article:}

Ali Razmjoo, Mohammad Ghadimi, Mehrzad Shams, Hoseyn Shirmohammadi. Design and Built a Research AUV Solar Light Weight. International Journal of Energy and Power Engineering. Vol. 4, No. 5, 2015, pp. 268-274. doi: 10.11648/j.ijepe.20150405.15

\begin{abstract}
Nowadays, renewable energy consumption especially solar energy and the number of vehicles using this kind of energy is increasing. One of the vehicles that can use solar panels to provide sufficient energy for movement is AUV. Autonomous underwater vehicle (AUV) is an unmanned underwater vehicle which is utilized to accomplish various missions autonomously. In this article constructing a solar submarine is studied. On the hull of the vehicle solar cells are installed, and then its velocity under the water is calculated. It's believed that the present research could result in an underwater vehicle which is able to move under the water and provide its own required electrical energy using solar cells.
\end{abstract}

Keywords: AUVs, Submarine, Diving and Climbing, Buoyancy Force, Solar Panel

\section{Introduction}

One of the important factors for economic growth and development is energy [1].The population of the world and its energy consumption is increasing, these ends up to use much more fossil fuel and inevitably it will be a world issue in the future; by the way, researchers decided to use sustainable energy resources. Nowadays, majority of countries have a plan for decreasing fossil fuel use and developing renewable energy. Note that many projects in different regions of the world are being done $[2,-4]$. Renewable energy is an essential alternative in order to reduce the $\mathrm{CO} 2$ emission which, in turn, leads to healthy environment. European Union Energy started some programs for decreasing greenhouse gases emission aiming to achieve up to $20 \%$ decrease by 2020 and $80 \%-95 \%$ decrease by 2050 by $[5,6]$. The fig 1. Shows Average Annual Growth Rates of Renewable Energy Capacity from 2007 to 2012.[7]

AUVs are one of the solutions for this purpose. They are vehicles which are able to help us in different fields such as missions in offshore oil and gas platforms [8,9]. AUVs are relatively small, self- propelled with the capability to be controlled from different places; furthermore, they can help us in various underwater missions [10]. Rapid progress in AUVs development is increasing steadily. Meanwhile, electrical AUVs are used in order to scope activity in the oceans [11-15].

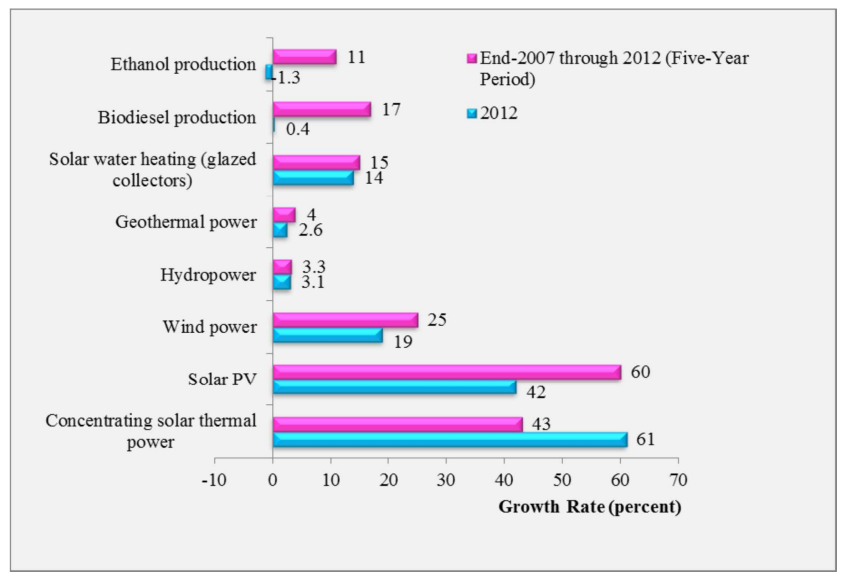

Fig. 1. Average Annual Growth Rates of Renewable Energy Capacity from 2007 to 2012 [7].

\subsection{Potential and Efficiency of Solar Energy}

Today role of solar energy is very clear in our live and using of Photovoltaic systems is a main subject in order to obtain necessary energy such as electrical energy [2].

Solar energy is a known energy that has much more benefits. It will be an important renewable source for producing electricity in the future. In most countries a large number of studies has been done on this kind of energy and how to 
consume it, and it is increasing continuously. According to the statistics the potential of solar radiation in tropical areas is more than other places. As the published data shows the annual irradiation in Europe is about $1000 \mathrm{KWh} / \mathrm{m}^{2}$, while in the middle east the value is approximately $1800 \mathrm{KWh} / \mathrm{m}^{2}$ [16-23].

\subsection{Efficiency of Solar Cells}

Technology of Solar cells for producing electricity was first introduced in the late 1950s, and then gradually developed [24]. At present Concentrate of Solar Power technology implementation in all of the world and using of solar power in variety equipments is growing fast [25]. The following table shows different modules, technologies and efficiency of solar cells. In this research module BP 7190 with technology CZ, SI, S. P. J and efficiency 15.1 elected.

Table 1. Efficiency and technology advances of solar cell [26].

\begin{tabular}{lll}
\hline Module & Technology & Efficiency \\
\hline Sun Power 315 & Mono-Si (S. P. J) & 19.3 \\
Sanyo HIP-205 BAE & CZ-SI, HIT, S. P. J & 17.4 \\
BP 7190 & CZ, SI, S. P. J & 15.1 \\
Kyocera KC 200GHT-2 & MC, SI, Standard Junction & 14.2 \\
Solar worlds w 185 & CZ-SI STD J & 14.2 \\
BPSX 3200 & MC-SI STD J & 14.2 \\
Suntech STP 260S 24V/b & MC or CZ SI STD J & 13.4 \\
Solar WORLDS W225 & MC-SI STD J & 13.4 \\
Ever Green Solar ES 195 & String Ribbon-SI STD.J & 13.1 \\
Worth Solar WS 1100 7/80 & CIGS & 11 \\
First Solar FS-275 & CDLE & 10.4 \\
Sharp NA-901-WP & A-SI/NC-SI & 8.5 \\
GSE Solar GES 120-W & CIGS & 8.1 \\
Mitsubishi heavy MA100 & A-SI-Single Junction & 6.3 \\
UNI-Solar PVL 136 & A-SI-Triple Junction & 6.3 \\
Kaneka T-SC(EC)-120 & A-SI-Single Junction & 6.3 \\
Schott Solar ASI-TM86 & A-SI/A-SI Same band Gap & 5.9 \\
EPVEPV-42 & A-SI/A-Si Same band Gap & 5.3 \\
\hline
\end{tabular}

There are several vital factors for solar cells which are dependent on many environmental features and weather parameters such as humidity, wind speed, sun intensity and so on. High temperature increases the conductivity of cells. Semiconductor properties define suitability of a material for being used in PV cells. One of these properties is called band gap, which is the energy gap an electron must cross to promote from the valence band to the conduction band. Low temperature reduces the band gap of the semiconductor. Fig. 2 illustrates the dependency of band gap on temperature and its efficiency with respect to the content elements of solar test. Recent studies called band gap method has proved that the efficiency of solar cells degrades as a result of increase in temperature. According to this method as temperature increases, band gap is reduced [27-29]. Fig. 2 shows band gap temperature and efficiency.

In order to provide required energy a $42.5 \mathrm{~cm}$ of solar panel was used. The solar panels charge two batteries. Efficiency of solar panels is $15 \%$ (BP 7190 module with CZSI, SP. J technology). The proposed submarine is not strong enough to be used in deep water. Furthermore, it is a research vehicle whose time of testing was brief, approximately 10 minutes. Therefore, the installed solar panel is suitable for short times and charging in limited times, to support a wider time span more panels are needed. According to the obtained figures, total efficiency is obtained as follows.

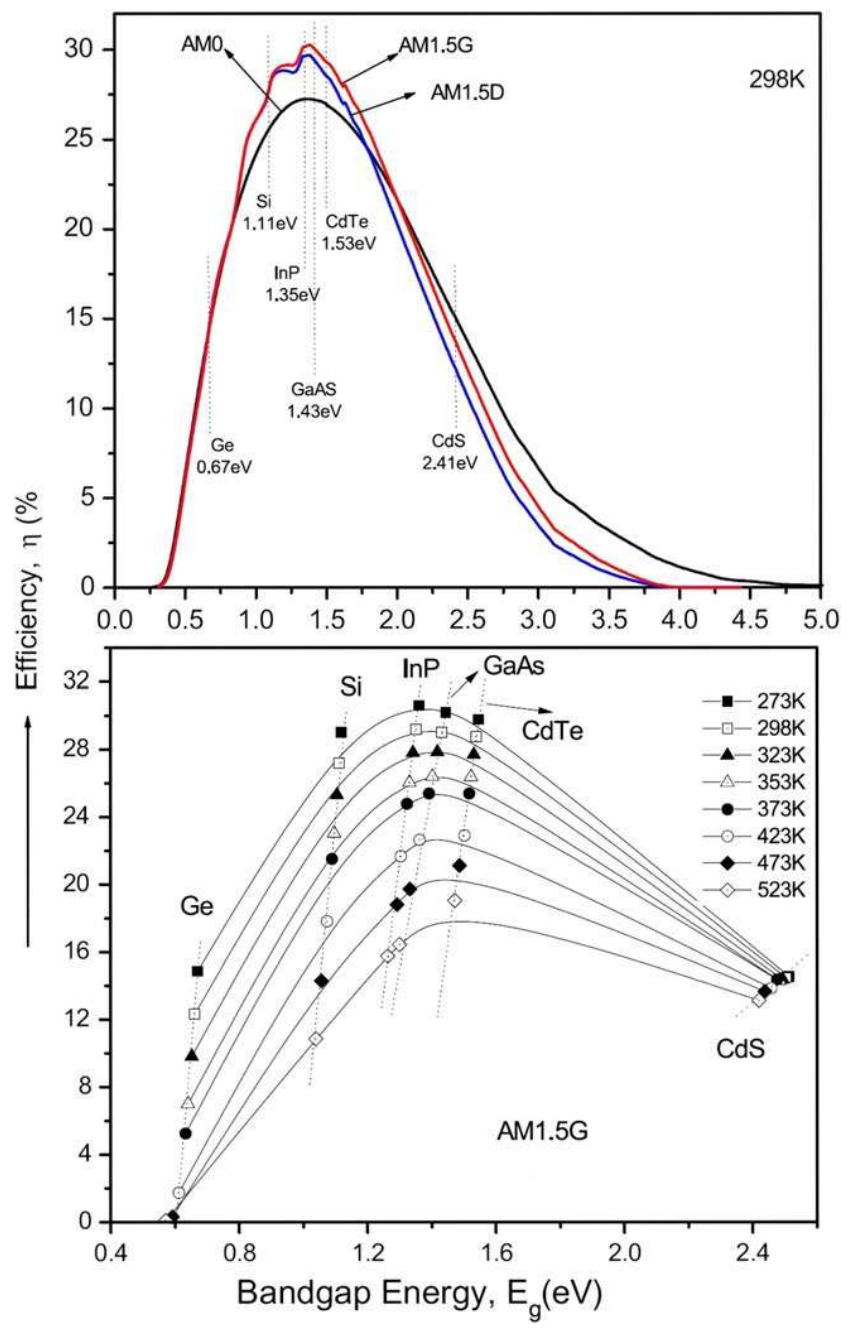

Fig. 2. Dependency of the band gap temperature and efficiency [26].

Considering the efficiency of $50 \mathrm{~m} \mathrm{~A}$ (Ampere) per solar panel, three panels (whose total efficiency would be equal to $0.1 \mathrm{~m} \mathrm{~A})$ and the voltage required to charge the batteries (which is 6 volt), one may conclude that more solar panels must be used to meet our requirements; otherwise, the panels must be exposed to the sun for longer time period in order to properly provide the required power. It can be said that we require 120 solar panels to provide 6 volt (given the value of $50 \mathrm{~m} \mathrm{~A}$ ), considering the economic costs, a new question arises; whether the project is economically feasible or not. To answer this question, we must say that a motorcycle works with a power of 6 or 12 volts; and in addition to air pollution, fuel costs must be considered to supply the amount of electricity that is obtained from the fuel. Although initial costs are higher in the projects that are done (or are in progress) on solar cells, these costs would be rational in long term view. Fig. 3 shows the solar panels installed on submarine. 


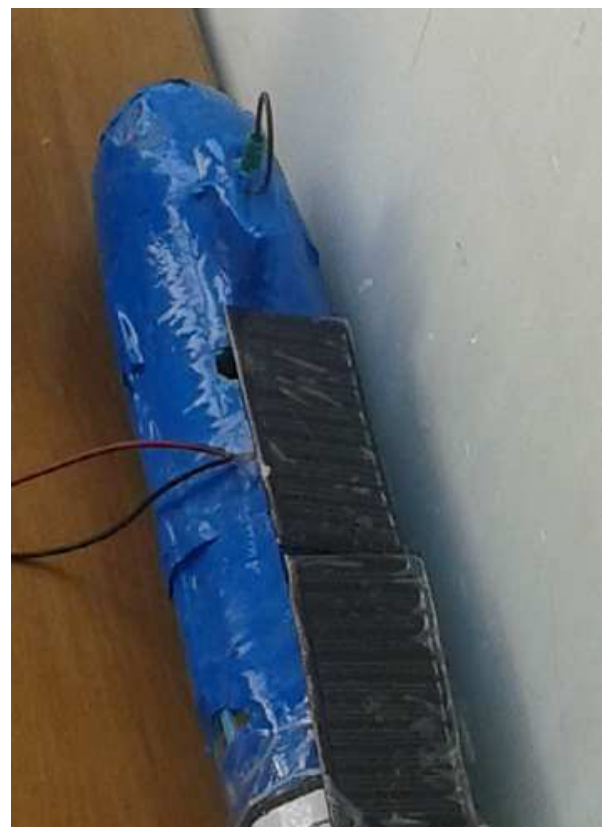

Fig. 3. Solar panels installed on submarine.

\section{Mechanic of Designing the Vehicle}

As mentioned before AUVs are small in size, typically capable and useful, all submarines have an outside and an inside hull. For this project the outside part is made of fiber glass, and has a high resistance against water pressure in the examined pool. Note that required power is supplied by batteries. Before the design is proved, the hull needs ring profile equation (Myring 1976), a known method to produce minimum drag force to a given fineness ratio $(1 / \mathrm{d})$. It could be said it is the ratio of its length to its maximum diameter. Figure 4 shows the sample design of the vehicle. [11, 31, 32]

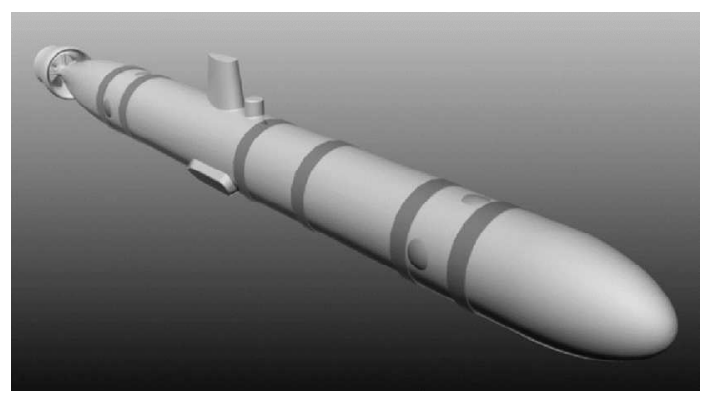

Fig. 4. Sample design of the outside hull of the vehicle [30].

\subsection{Inside Layout of a Submarine}

In addition to the outside hull equipment, a space is also needed in the internal equipment. The above mentioned design used 3 electrical motors which rotate. It also includes a shaft and a blade on the external body, to provide electrical power a cable is used to connect the motor to the battery, an empty space for the battery is then needed. In this project common vessels are used in the inside hull, in the main vessel the motor cable and the blade are located while the battery is located under it.

\subsection{Diving, Climbing and Move for Stability}

As mentioned before, this system uses a common hull that has an inside part. It means when the hull becomes full of water vehicle can dive in water using its weight. Afterwards, it can climb via climb motor. As the figure below shows for inlet water a window is used together with a support in order to avoid extra water. Fig. 5 shows the water inlet window on the submarine.

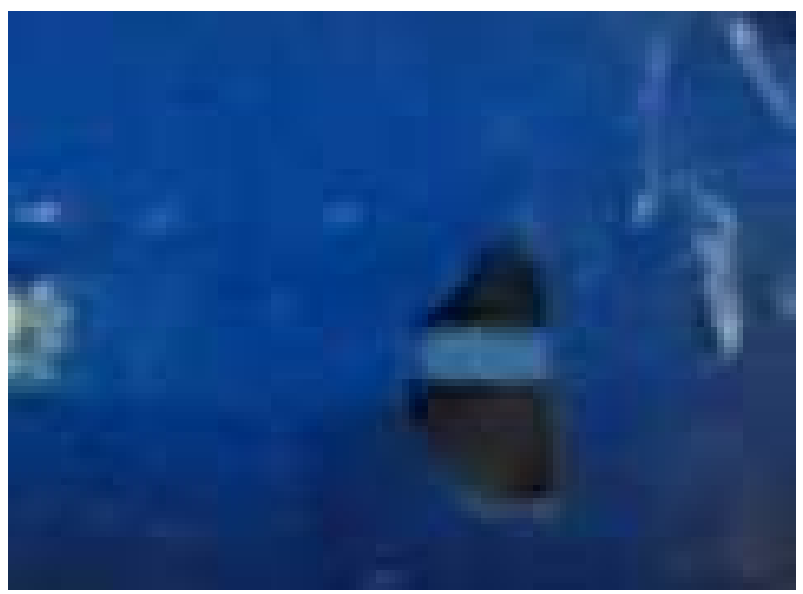

Fig. 5. Water inlet window.

In order to Control Surfaces as well as Depth Control Using Archimedes principle, weight of the vehicle was calculated in air and in water to achieve desired buoyancy of the vehicle in water.

\subsection{Stability}

Stability is an important issue regarding every sea vehicle and its associated rules need to be known. To be more detailed about this rule, according to Archimedes' principle, for any object immersed in a fluid, a force is exerted on the object by the fluid, which is equal to the weight of the displaced volume of the fluid, this is called buoyancy force. The fig. 6 shows a kind of instance for body and inertia coordinate systems which are an important law.

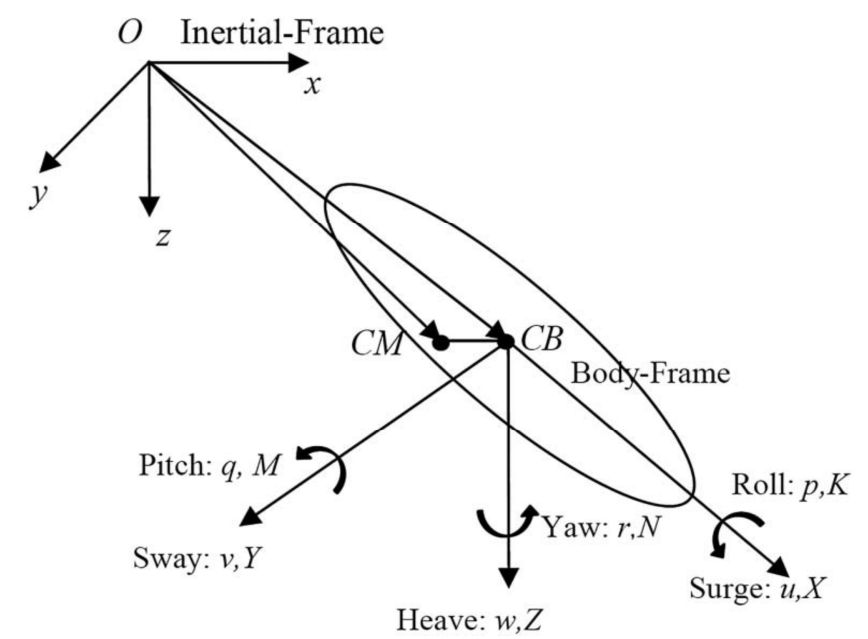

Fig. 6. Body and inertia coordinate systems [33]. 
Actually stability for everybody at first depend to integration all members. To be more detailed about this law, according to Archimedes' principle, for any object immersed in a fluid, a force is exerted on the object by the fluid, which is equal to the weight of the displaced volume of the fluid, this is called buoyancy force.

Positive buoyancy mode $(\mathrm{W}>\mathrm{B}$, weight smaller than buoyancy)

Neutral buoyancy mode ( $\mathrm{W}=\mathrm{B}$, weight and buoyancy are equal)

Negative buoyancy mode $(\mathrm{W}<\mathrm{B}$, weight greater than buoyancy)

Buoyancy force depends on the size of the body's seal; the submarine balance can be controlled by changing the buoyancy force. In this case, the size BG should be large enough to avoid feeling the movement of the inner weight. Such bodies are inherently stable in the vertical direction. If the immersed neutrally buoyant body is raised or lowered to a different depth (disturbance), this body will remain in equilibrium at that location (Cengel \& Cimbala, 2006). Also, from dynamic perspective size of BG has a great effect on the behavior of high-speed underwater submarine. Besides, BG builds a hydrostatic resistance of the body against the longitudinal momentum. $\mathrm{BG}$ is so important in the equilibrium of the submarine during diving and climbing [34]. Table 2 illustrates the characters of submarine include length, area, height, width, weight.

Submarine size:

Table 2. Characters of submarine.

\begin{tabular}{ll}
\hline character & amount \\
\hline Length & $75 \mathrm{~cm}$ \\
Area & $180 \mathrm{~cm}$ \\
Height & $7 \mathrm{~cm}$ \\
width & $5 \mathrm{~cm}$ \\
Wight & $1 \mathrm{~kg}$ \\
\hline
\end{tabular}

\section{Velocity Calculation}

Calculating the velocity of the submarine is an important step in order to estimate the power. Experiments are done in a pool with laminar flow in a pool located in Mosavi Street in Tehran, in 1 meter deep and in 3 states. These states include $1 \mathrm{~m}, 5 \mathrm{~m}$ and $10 \mathrm{~m}$ distances. The whole experiments showed that this submarine could traverse a distance of 48 meter per minute, thus the velocity of an underwater submarine, according to maritime knots is equal to 1.5 knot. Table 3 shows important parameters for test of underwater vehicle in the pool.

Table 3. Remarkable parameters for test of underwater vehicle in the pool.

\begin{tabular}{lccc}
\hline Parameter & Max & Min & Test time \\
\hline $\mathrm{T}$ (water) & 30 & 4 & 27 \\
$\mathrm{P}$ & 20 & 1 & 3 \\
$\mathrm{~T}$ (environment) & 35 & 4 & 10 \\
Deep & 1.50 & 40 & 80 \\
\hline
\end{tabular}

Also terminal is equal[35-39]:

$$
v i=\frac{\sqrt{2 m g}}{\rho \mathrm{A} c d}
$$

That in this article has:

$$
\begin{aligned}
v i & =\text { velocity } \\
m & =\text { mass } \\
g & =9.8 \mathrm{~g} / \mathrm{cm} \\
\rho & =\text { density } \\
A & =\text { Area } \\
c d & =\text { coefficient drag }
\end{aligned}
$$

\subsection{Laminar and Turbulent Velocity Experiments}

When an underwater vehicle moves under the water there are different situations, which affect the velocity, Pressure in different directions can even change the movements of the vehicle as well as reducing its speed. There is a table that shows calculated velocity for laminar and turbulent flow. Table 4 illustrates velocity terminal that calculated in laminar and turbulent flow in poor water, As table shows, velocity terminal in laminar and turbulent flows in pool water are calculated. Actually in this experiment evaluation is performed for two flows. Results demonstrate that there are an obvious difference in submarine movement. Moreover, the submarine in turbulent flow needs more energy.

Table 4. Velocity terminal that calculated in laminar and turbulent flow in poor water.

\begin{tabular}{lcc}
\hline Time (s) & Laminar Flow $\mathbf{~ m} / \mathbf{s}$ & Turbulent Flow $\mathbf{~ m} / \mathbf{s}$ \\
\hline 6 & 4.869 & 2.841 \\
12 & 9.738 & 5.682 \\
18 & 14.607 & 8.523 \\
24 & 19.476 & 11.364 \\
30 & 24.345 & 14.205 \\
36 & 29.214 & 17.046 \\
42 & 34.083 & 19.887 \\
48 & 38.952 & 22.728 \\
54 & 43.821 & 25.569 \\
60 & 48.690 & 28.410 \\
\hline
\end{tabular}

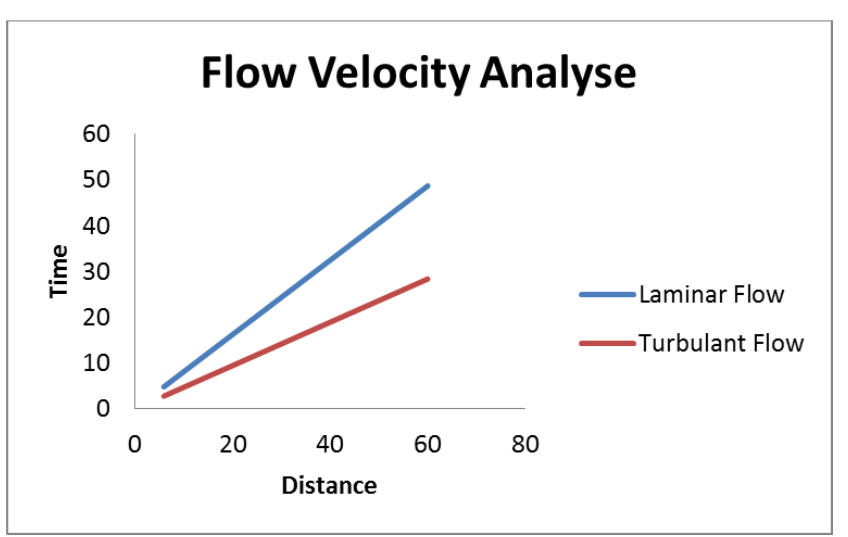

Fig. 7. Velocity terminal that calculated in laminar and turbulent flow.

Fig. 7 shows analysis of velocity in laminar and turbulent 
flows. As can be seen there are a direct line for velocity in different points. In this figure, it is obvious that for laminar flow from first point to final point velocity is not reduced while in turbulent flow it decreases because the water has up and down flow and submarine cannot move appropriately.
A remarkable thing for each under water vehicle it is relation between Reynolds and movement in different levels of, turbulent fluids and resistance against water pressure fluid the fig 8 shows movement a vehicle in the water and different resistances.

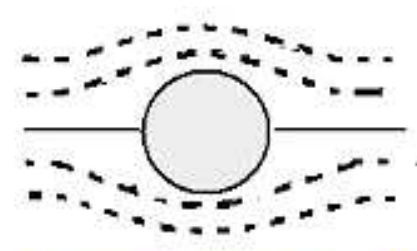

Reynolds Number $\sim 10$

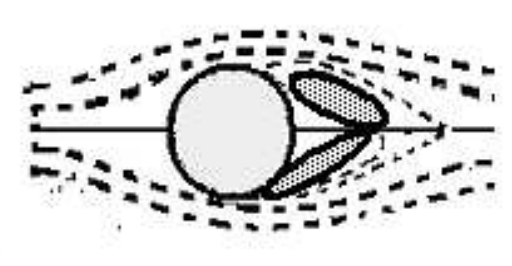

Reynolds Number \% 50

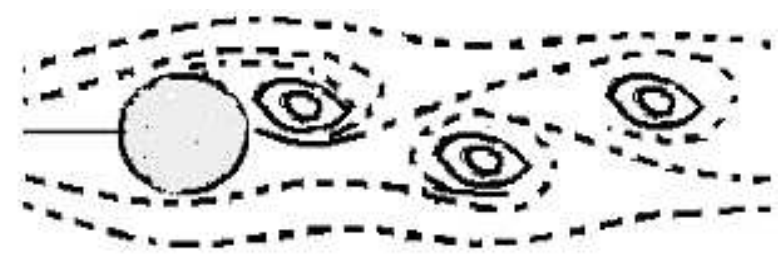

Reynolds Number $\sim 100$

Fig. 8. Resistance against water pressure for a underwater vehicle to Reynolds number [40].

As it obvious in Reynolds number 100 there are a pressure of all direction to vehicle from all directions.

After up points about move of vehicle it needs to explain about Member and weight vehicle, table 5 shows the member and weight them which consists servo motor, solar panel, rechargeable battery, hull, cover of battery, charger, of battery, blade, weight of beam, weight of keeper static and in the end total weight of submarine.

The following table shows the utilized equipment and the weight of each one.

Table 5. Members and weight them.

\begin{tabular}{lllll}
\hline \multirow{2}{*}{ Serial } & \multirow{2}{*}{ Description } & Quantity & \multicolumn{2}{l}{ Weight (g) } \\
\cline { 3 - 5 } & & & Single & Total \\
\hline 1 & Servo motor & 3 & 35 & 105 \\
2 & Solar panel & 3 & 10 & 30 \\
3 & Rechargeable battery & 5 & 40 & 200 \\
4 & Hull & 1 & 300 & 300 \\
5 & Cover of battery & 1 & 75 & 75 \\
6 & Charger, of battery & 1 & 90 & 90 \\
7 & Blade & 6 & 16.6 & 100 \\
8 & Weight of beam & 1 & 50 & 50 \\
9 & Weight of Keeper static & 1 & 50 & 50 \\
Total weight & & & & 1000 \\
\hline
\end{tabular}

\subsection{Submarine's Battery and Controller}

Strong points of lithium batteries include longer lifespan, high energy density and providing electricity when discharging. A lithium battery can produce a voltage between $1.5 \mathrm{v}$ to about $3.7 \mathrm{v}$. (iron disulfide [li - FeS2 (FR)] Propylene Carbonate, dioxolane, dimethoxymethane...v $=1.4$ 1.8 types). As we know batteries are good power sources for many equipment and industrial applications. To provide electricity, solar panels are connected in series and convert the solar energy to electricity in order to charge batteries. To supply electricity of the proposed submarine, $1.5 \mathrm{~V}$ rechargeable batteries are used. four ultra-light lithium type batteries are exploited to obtain, a voltage source of $6 \mathrm{~V}$. The required power of 6 volts $50 \mathrm{~m} \mathrm{~A}$ is supplied through connecting batteries poles to the solar panels via power cables. There are some other vehicles that are powered by solid polymer electrolyte Fuel Cell (PEFC) (Hyakudome et al, 2001), aluminum/oxygen full Cell (vestgard et al, 2001) and solar cells,[41-43]. The following figure shows control radio used for the submarine.

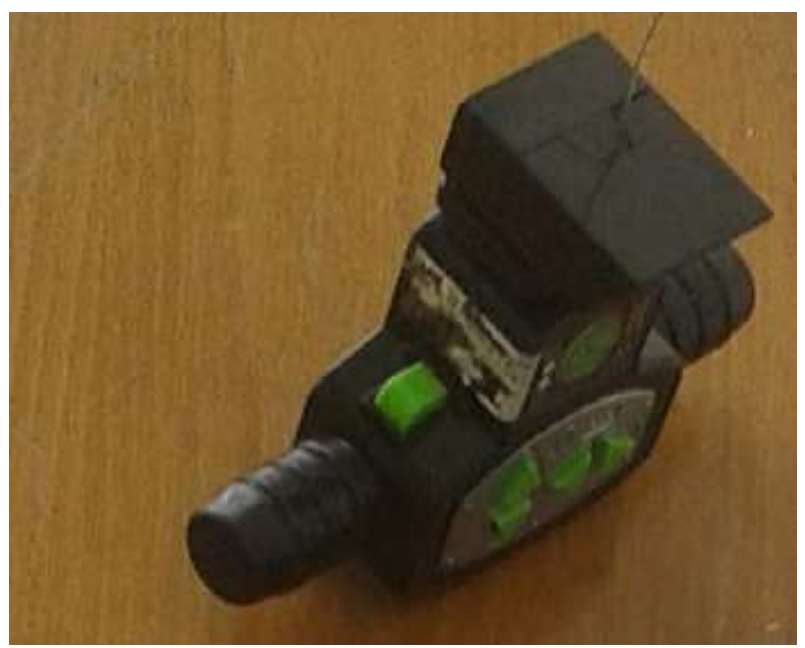

Fig. 9. Used radio controller type of solar submarine for near distance.

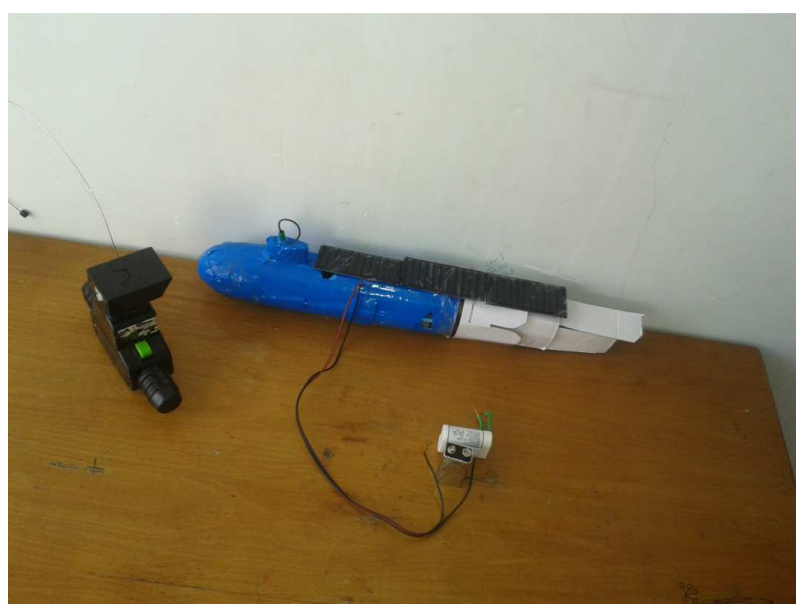

Fig. 10. Research solar underwater vehicle.

\section{Conclusion}

Nowadays much interest is shown in autonomous unmanned systems. To develop submarines solar cells are more beneficial. This research has three goals which are 
mentioned in the following.

First, making a light but strong against the water pressure submarine. Second calculating the velocity of submarine under the water and, third, calculating the amount of the battery charge for submarine movements. To construct the submarine's hull a kind of light but strong fiberglass is selected. Then, 3 panels of solar cells with $15 \%$ capability (BP 7190 module with technology CZ-SI, SP. J) are installed on the hull. Finally the amount of time needed for the charge to afford the movements and the velocity of submarine in the laminar flow in the pool are calculated.

\section{References}

[1] Orhan Ekren and Banu Yetkin Ekren Size Optimization of a Solar-wind Hybrid Energy System Using Two Simulation Based Optimization Techniques, Volume 85, Issue 11, pp 1086-1101, 2008.

[2] Jasim Abdulateef, Simulation of solar off- grid photovoltaic system for residential unit, International Journal of Sustainable and Green Energy; vol 4(3-1): pp, 29-33,2014.

[3] Farivar Fazelpour, Nima Soltani, Marc A. Rosen, Wind resource assessment and wind power potential for the city of Ardabil, Iran, International Journal of Energy and Environmental Engineering, Vol 3: pp 1-8, 2012.

[4] Mohammad-Ali Yazdanpanah Modeling and sizing optimization of hybrid photovoltaic/wind power generation system, journal of industrial engineering international, Vol 1 pp, 1-14, 2014.

[5] Warit Werapuna, Yutthana Tirawanichakul, Watsa Kongnakorn, Jompob Waewsak, An Assessment of Offshore Wind Energy Potential on Phangan Island by in Southern Thailand, Energy Procedia 52 pp 287 - 295,2014.

[6] Georg Felber and Gernot Stoeglehner, Onshore wind energy use in spatial planning a proposal for resolving conflicts with a dynamic safety distance approach, Energy Sustainability and Society, pp 4-22, 2014.

[7] Fahime Heidarzade1, Mohammad Hossein Morshed Varzandeh, Placement of Wind Farms Based on a Hybrid Multi Criteria Decision Making for Iran World Sustainability Forum the 4th sustainability forum, 2014.

[8] Chris Schwarz, Geb Thomas, Kory Nelson, Michael Mac Cray, Nicholas Schlarmann, toward autonomous vehicles, p 67, 2013.

[9] Zool H Ismail, Ahmad A. Faudzi and Matthew W. Dunnigan, Tracking control scheme for multiple autonomous underwater vehicles subject to union of boundaries, Procedia engineering pp1176-1182, 2012.

[10] Paul G. Fernandez, Pete Stevenson, Andrew S Brierley, Fredrick Armstrong And e John Simmonds, autonomous underwater vehicles: future platform for fisheries acoustics, ICEC journal of Marine Science, Vol 60 pp 684-691.2003.

[11] Tae- Hwan joung, karlsammut, Fangpo, He, And Seung-Keon Lee, Shape optimization of an autonomous underwater vehicle with a ducted propeller using computational dynamics analysis, International journal Navigation Archit ocean engineering Vol 4: pp 44-56, 2012.
[12] Hu Yuli, wang Jiajun, Study on power generation and energy storage system of solar powered Autonomous Underwater Vehicle (SAUV)2012 international Conference on Future Energy, Environmental, and material Energy procedia 16, pp. 2049-2053, 2013.

[13] Francisco Garcia-Cordova, Antonio Guerrero-Gonzales, Intelligent navigation for a solar powered unmanned underwater vehicle, international journal of advanced robotic systems, Int J Adv Robotic Sy, Vol. 10, 185:2013.

[14] Chunfeng Yue, Shuxiang Guo, Liwei Shi, hydrodynamic analysis of the Spherical underwater robot SUR-II, international journal of advanced robotic systems Vol 10,247,2013.

[15] Falmouth scientific, Inc, solar powered autonomous underwater vehicle (SAUV), September 2005.

[16] Alejandro Mendez, Teresa j Leo, And Miguel a Herreros, Current state of technology of full cell Autonomous Underwater Vehicle, 1st international e-conference on energy 14-31 march, 2014.

[17] M. Jamil Ahmad and G. N. Tiwari, Optimization of Tilt Angle for Solar Collector to Receive Maximum Radiation, the Open Renewable Energy Journal, pp 19-24,2009.

[18] T. Srinivas, B. V. Reddy, Hybrid solar-biomass power plant without energy storage Case Studies in Thermal Engineering pp75-81, 2014.

[19] Andhy Muhammad Fathonia, b, N. Agya Utamab, Mandau A. Kristianto, A Technical and Economic Potential of Solar Energy Application with Feed-in Tariff Policy in Indonesia, Procedia Environmental Sciences pp 89 - 96,2014.

[20] Khai Mun Ng, Assessment of solar radiation on diversely oriented surfaces and optimum tilts for solar absorbers in Malaysian tropical latitude, International Journal of Energy and Environmental Engineering 5:5 doi:10.1186/2251-6832$5-5,2014$

[21] Pragya sharma, Tirumalachetty Harinariayna, Solar energy generation potential along national high ways, international of Energy and environmental Engineering, pp 4-16, 2013.

[22] Enda Flood, K. McDonnell, F. Murphy and G. Devlin, A Feasibility Analysis of Photovoltaic Solar Power for Small Communities in Ireland The Open Renewable Energy Journal, pp 78-92, 2011.

[23] Souvik Ganguli, Jasvir Singh, Estimating the Solar Photovoltaic generation potential and possible plant capacity in Patiala International a journal of applied engineering Research, Dindugul Vol 1, pp 253-260,2010.

[24] Xiaoming Wang, Jian zhongshang, Zirong Luo, Li Tang Xiangpo Zhang, Juan li. review of power system and environmental energy conversion unmanned for underwater vehicles, Renewable and sustainable energy review pp19581970, 2012.

[25] Ramadan Abdiwe, Markus Haider, Investigations on Heat Loss in Solar Tower Receivers with Wind Speed Variation, Vol 4(4): pp,159-165,2015.

[26] Farivar fazelpour, Majid Vafaiepour, Omid Rahbari, Considerable Parameters of Using PV cells for Solar-Powered aircraft, Renewable and Sustainable Energy Review, 22 pp 8191, 2012. 
[27] Singh P, Ravindra NM. Temperature dependence of solar cell performance an analysis. Solar Energy Materials \& Solar Cells 2012; 101:36-45.

[28] Ali A. Sabzi Parvar, A simple formula for estimating global solar radiation in central arid deserts of Iran Renewable Energy pp1002-1010, 2008.

[29] Thomas huld, Ralph Gottschalg, and Hans Georg Beyer, Marko topic, mapping the performance of PV modules, effects of module type and data averaging solar energy 84 , pp 324 $338,2010$.

[30] S Gomariz, J. Prat, A. Arbos, O. Palares, C Vinolo, Autonomous vehicle development for vertical underwater observation, journal of maritime research vol 6 No 2, p 9,2009.

[31] Jenna Brown, Chris Tuggle, Jamie Mac Mahan, Ad Reniers, The use of autonomous vehicles for spatially measuring mean velocity profiles in rivers and estuaries. Intel Servo Robotics 4:pp 233-244,2011.

[32] Masoud Hekami Fard, Milad Bandegani, Mohammad Nasri, Mysam Yazdi, Design a solar submarine Montreal model, $13^{\text {th }}$ conference nation nautical industrial,2011.

[33] M. H. Shafiei and T. Binazadeh, Movement control of a variable mass underwater vehicle based on multiple-modeling approach, Systems Science \& Control Engineering: An Vol. 2, pp 335-341, 2014.

[34] Roy Burcher, Louis J Rydill, Concepts in Submarine Design Cambridge University Press. 170 publish 1995.

[35] Terminal Velocity, NASA Glenn Research Center. Retrieved March 4, 2009.
[36] Huang, Jian, Speed of a Skydiver (Terminal Velocity), The Physics Factbook. Glenn Elert, Midwood High School, Brooklyn College, 1999.

[37] All About the Peregrine Falcon archived. U.S. Fish and Wildlife Service. December 20, 2007. Archived from the original on March 8, 2010.

[38] The Ballistician, Bullets in the Sky. W. Square Enterprises, 9826 Sagedale, Houston, Texas 77089, march 2001.

[39] Robert H. Perry; Cecil Chilton (eds.). Chemical Engineer's Handbook (fifth ed.). pp. 5-62. ISBN 978-0070494787.

[40] A. Yashodhara Rao, A. Sarada Rao, Appajosula S. Rao, Dynamics of Fluid Flow around Aerofoil, and Submarine: Effect of Winglets, The International Journal of Engineering And Science (IJES), Vol 2 pp 39-46, 2013.

[41] Uger Ecin, Josep Gilmartin, Jonathan Grilo, Minhaj Khan, Stephanie Limb, James Parsons. Multi-Disciplinary Design Project (MDDP) 2012/13 Underwater Vehicle for Submarine Cable Repair Final Report Monday, 14 ${ }^{\text {th }}$ January 2013.

[42] David A. Schoen Wald, AUVs, in space, Air, water, and on the Ground. IEEE control systems Magazine December vol 20 ,pp 15-18, No 6,2000.

[43] Khairul Alam, Tapabrata Ray, Sreenatha G. Anavatti. A Brief taxonomy of autonomous underwater vehicle design literature, University of new south Wales, UNSW Canberra, Act 2600 Australia, Ocean Engineering Vol 88, pp 627-630, 2014. 